\title{
ПАРАМЕТРИЧЕСКОЕ ОПИСАНИЕ НАЦИОНАЛЬНЫХ И РЕГИОНАЛЬНЫХ ИННОВАЦИОННЫХ СИСТЕМ
}

\author{
Лысенкова М.А.
}

Целью исследования является получение и обоснование параметрического описания национальных и региональных инновационных систем. $B$ работе показано, что для параметризации национальной инновационной системы целесообразно использовать два параметра стохастической производственной функции, описывающей зависимость результата инновационной активности от размера инновационного пространства. Рост каждого из этих двух параметров свидетельствует о равномерном развитии наџиональной инновационной системьл.

DOI: $10.20537 /$ mce2020econ15

Введение. Процессы глобализации, повышение уровня конкурентоспособности стран требуют решения новых и сложных задач технологического и научного развития. Последние научные статьи хорошо освещают вопрос влияния университетов и научных институтов на возможность страны конкурировать на мировых позициях [1,2]. Автор [3] указывает в своей статье, что очень важна грамотная региональная политика и экономика в процессе создания и развития институтов и университетов, поэтому только в этом случае они смогут оказывать влияние на экономику страны в целом. Развитие и поддержка научных институтов и университетов приводит к росту патентной активности в стране. В статье [4] на основе многомерной классификации выделяются группы стран, схожие по уровню патентной активности. Отмечается, что страны с самыми высокими показателями инновационной активности - это Южная Корея, США, Китай и Япония. Согласно глобальному инновационному индексу, опубликованному Всемирной организацией интеллектуальной собственности (ВОИС) в 2016 г., США и Япония выступают среди лидеров рейтинга в плане «качества инноваций». ВОИС отмечает большой прорыв Китая, который вошел в число 25 ведущих странноваторов в мире. Так же стоит отметить, что США, Япония и Китай по данным ВОИС стали странами лидерами по числу международных па- 
Лысенкова М.А. Параметрическое описание национальных и региональных..., стр. 156-161 Lysenkova M.A. Method of parametric description of national and regional..., pp. 156-161

тентных заявок. Согласно докладу «Глобальный инновационный индекс» в 2017 г., подготовленному совместно Корнельским университетом, школой бизнеса INSEAD и ВОИС, рейтинг ведущих странноваторов возглавляют Швейцария, Швеция, Нидерланды и США.

\section{Параметрическое описание инновационных систем разных} стран. Статья [5] продолжает цикл работ авторов касательно параметрического описания инновационных систем разных стран. На современном этапе экономика знаний играет большую роль в функционировании общества. Инновационное развитие выводит общество на новый уровень. Регионы стремятся добиться международной конкурентоспособности. Возникает необходимость формирования согласованного видения научного и технологического будущего страны. Большинство мировых экспертов сходятся в том, что необходимо укрепление взаимодействия бизнеса, науки (образования) и государства.

В работе [6] была доказана возможность использования инновационного пространства в качестве фактора, позволяющего оценить инновационную активность региона. Так же было обосновано преобразование многофакторной производственной функции, определяющей зависимость результата инновационной активности региона РФ от совокупности характеристик науки и бизнеса, к модели М1 вида

$$
\ln Q_{i}=c+\delta \ln V_{i}+v_{i}-u_{i} .
$$

Здесь $Q_{i}$ - результат инновационной активности региона $i$ ( $Q_{i}=$ pat $_{i}$ - число выданных патентов, или число международных патентных заявок); $V_{i}=S_{i} \times B_{i}$, где $S_{i}$ - количество высших учебных заведений; $B_{i}=b u z_{i}$ - число предприятий региона, $c, \delta$ - параметры. Величина $V_{i}=S_{i} \times B_{i}$ - число потенциальных парных связей между организациями, выполняющими научные исследования и предприятиями, которое характеризует размер инновационного пространства региона. Случайная составляющая $v_{i}-u_{i}$ отражает результаты воздействия на процесс инновационной деятельности региона факторов неопределенности и факторов эффективности.

Результаты построения модели, представленные в работе, получены с использованием статистических данных из официальных статистических сборников и баз данных (Росстат, OECD и др.) В данной статье использовались статистические данные по регионам РФ, США, Швейцарии, Японии и Китая. 
На рис. 1 представлено параметрическое описание $(\delta, c, t)$ инновационных систем Швейцарии, РФ, США, КНР и Японии по международным патентным заявкам для 2012 г. По оси абсцисс оценка константы $c$, по оси ординат - оценка эластичности $\delta$, полученные по модели М1 для 2012 г. Для каждой точки указан год.

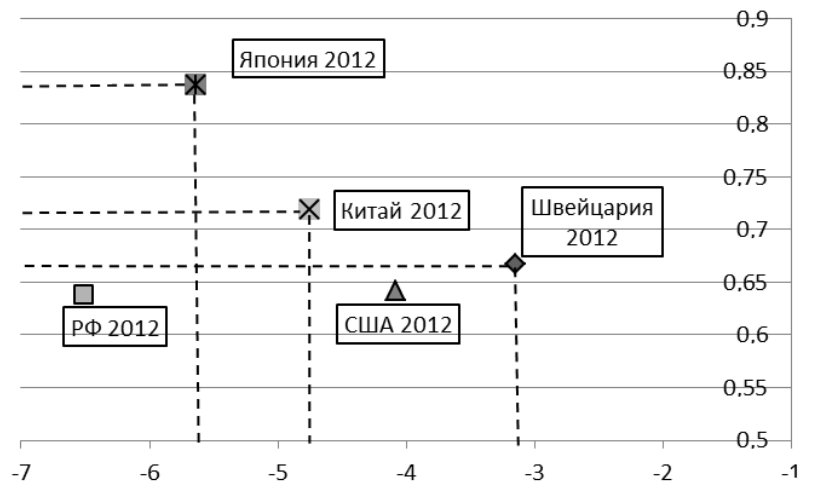

Рис. 1. Параметрическое описание инновационных систем РФ, Швейцарии, США, Китая и Японии по международным патентным заявкам.

Параметры Японии, Китая и Швейцарии для 2012 г. обладают свойствами парето-оптимальности. Можно сделать вывод, что влияние науки и бизнеса на результаты инновационной активности в Японии, Китае и Швейцарии выше, чем в РФ и США.

Параметрическое описание национальной и региональных инновационных систем может служить основой для межстрановых сопоставлений влияния науки и бизнеса на результаты инновационной активности, кластеризации национальных и региональных инновационных систем с целью использования опыта государственного и регионального управления инновационным развитием.

На рис. 2 представлено параметрическое описание $(\delta, c, t)$ инновационных систем Швейцарии, РФ, США и КНР по международным патентным заявкам для 2008, 2011, 2012 и 2013 гг. и Японии по международным патентным заявкам для 2006 и 2012 гг. По оси абсцисс - оценка константы $c$, по оси ординат - оценка эластичности $\delta$, полученные по модели М1 для 2008, 2011, 2012 и 2013 гг. Для каждой точки указан год. 
Лысенкова М.А. Параметрическое описание национальных и региональных..., стр. 156-161 Lysenkova M.A. Method of parametric description of national and regional..., pp. 156-161

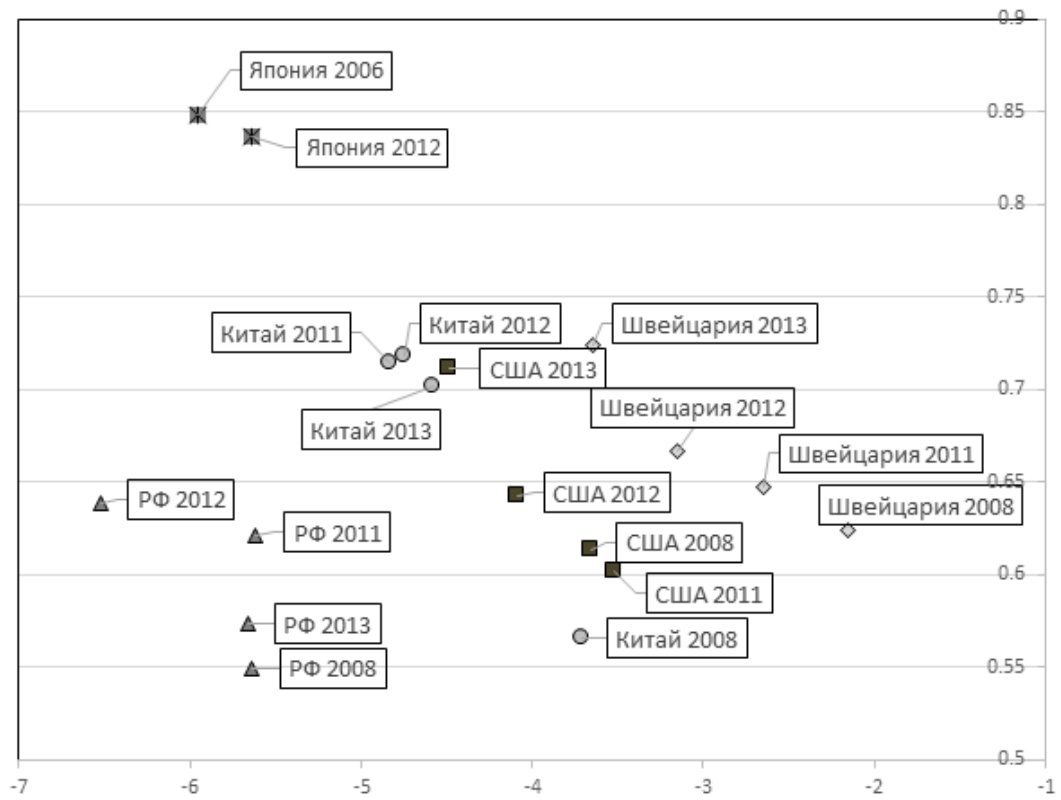

Рис. 2. Параметрическое описание инновационных систем РФ, Швейцарии, США, Японии и Китая по международным патентным заявкам.

В рассмотренном диапазоне времени свойством паретооптимальности обладают параметры инновационных систем Японии, Китая и Швейцарии.

Заключение. В соответствии с концепцией глокализации [7], неэффективность региона в группе регионов, имеющих близкие характеристики дифференциации, обусловлена тем, что он не использует в полной мере свои особенности и доступные возможности развития, то есть, относительно неэффективно использует свои ресурсы. В качестве характеристики качества управления региональной инновационной системой может рассматриваться техническая эффективность использования инновационного пространства $[8,9]$. При этом допустимо прямое сравнение региональных инновационных систем, функционирующих в рамках общей национальной инновационной системы, так как в этом случае оценки технической эффективности, полученные на основе общей модели М1, являются сопоставимыми. 
Показано, что для параметризации национальной инновационной системы целесообразно использовать два параметра стохастической производственной функции, описывающей зависимость результата инновационной активности от размера инновационного пространства: эластичность результата инновационной активности региона по размеру инновационного пространства и константу модели стохастической границы. Рост каждого из этих двух параметров свидетельствует о развитии национальной инновационной системы. Межстрановое сопоставление связано с поиском множества парето-оптимальных инновационных систем в пространстве двух параметров.

\section{СПИСОК ЛИТЕРАТУРЫ}

1. Blanco Ramirez G. Jean Baudrillard's radical thinking, and its potential contribution to the sociology of higher education illustrated by debates about 'WorldClass' universities // International Studies in Sociology of Education. 2017. № 26(4). P.337-352. DOI: 10.1080/09620214.2017.1322913

2. Sitnicki, M.W. Determining the Priorities of the Development of EU Research Universities Based on the Analysis of Rating Indicators of World-Class Universities // Baltic Journal of European Studies. 2018. Vol.8 (1). P. 76-100. DOI: 10.1515/bjes-2018-0006

3. Гранберг А.Г. Актуальные проблемы регионального развития и региональной политики // Социально-экономические реформы: региональный аспект. 2002. № 4. С.19-23.

4. Архипова М.Ю., Карпов Е.С. Анализ и моделирование патентной активности в России и развитых странах мира // РИСК: Ресурсы, Информащия, Снабжение, Конкуренция. 2012. № 4. С.286-293.

5. Афанасьев М.Ю., Лысенкова М.А. Подход к анализу и сопоставлению национальных инновационных систем на примере России и других стран // Вестник Воронежского государственного университета инженерных технологий. 2019. Т. 81. С. 434-442.

6. Айвазян С.А., Афанасьев М.Ю., Кудров А.В., Льссенкова М.А. К вопросу о параметризации национальной инновационной системы // Прикладная эконометрика. 2017. №1 (45). С.29-49.

7. Robertson R. Globalization: Social Theory and Global Culture. L., 1992. 
8. Aivazyan S., Afanasyev M. Kudrov A. Indicators of Regional Development Using Differentiation Characteristics // Montenegrin Journal of Economics. 2018. Vol. 14, No. 3. P.7-22.

9. Афанасьев М.Ю., Кудров А.В., Лысенкова М.А. Об одном подходе к сравнению регионов разных стран по оценкам технической эффективности инновационного пространства // Экономический анализ: теория и практика. 2019. T.18 №9 (492). C.1753-1774.

\section{METHOD OF PARAMETRIC DESCRIPTION OF NATIONAL AND REGIONAL INNOVATION SYSTEMS}

\section{Lysenkova M.A.}

The purpose of the study is to obtain and justify a parametric description of national and regional innovation systems. In this paper, we have obtained estimates of the technical efficiency of using the innovation space. they allow us to describe the regional innovation system. It is shown that for parameterization of the national innovation system, it is advisable to use two parameters of the stochastic production function that describes the dependence of the result of innovation activity on the size of the innovation space. The growth of each of these two parameters indicates the uniform development of the national innovation system. 